\title{
Challenges in Drug discovery: Can We Improve Drug Development
}

\author{
Balakrishnan Arun \\ Vice President, External Liason, Screening and Natural Products. \\ Piramal Life Sciences Limited, 1 Nirlon Complex, Goregaon (East), Mumbai 400063, India
}

\section{Technology drivers in drug discovery}

Scientific advancements in healthcare are driven by innovations in different areas like, understanding the pathogenesis of a disease, development of technologies for diagnosis, and treatment of the disease. The advent of molecular pathogenesis has helped us to understand the complex mechanisms that are involved in a specific disease. This change has heralded several novel discoveries in the area of biological sciences and healthcare. Bryan et al., (2009); Hart et al., (2009); Matta et al., (2009).

However, several challenges are unmet and there is always a need to compensate our resources in fighting to solve issues at a basic science level and also for the development of new drugs and new approaches for treatment. This challenge will continue and despite trying to better ourselves with knowledge, we appear to be far behind in conquering many diseases. There is always a quest for new knowledge that is available today for any specific medical condition. There are several unknowns in this pursuit, thus finding a novel drug for a disease is always a challenge. Following the path from discovery of a molecule through the road of development is complex and involves time, money and multiple disciplines to move it ahead.

Despite efforts to hasten the process of drug development using innovative technologies, the current efforts still appear to be ineffective. Several novel strategies like academia-industry interactions that foster a conversion of novel technologies to product and public - private funding etc have not helped to conquer several diseases. In fact, it appears that the efficiency has slipped. Therefore, it becomes important to identify the areas in the development chain that needs to be improved or methods by which one can hasten the process.

\section{Translation of basic research to development of lead com- pound}

Pharmaceutical industry and drug discovery research applied all the basic scientific data and have helped develop procedures and guidelines that enable the conversion of such information into useful tools that can be used to treat or intervene in the progression of disease. In order to address the question why discovery productivity has slipped despite large investments, several reports indicate that between 2005-2006, the funding for drug discovery rose from $\$ 48$ billion to $\$ 94$ billion. But the curve of submissions of new drugs and biologics to FDA is in the opposite direction, a mirror image of the investment curve. The major concern is related mainly to the costs of preclinical and clinical trials study which is called the critical path.

\section{Early drug discovery genomics and proteomics driven}

The flux of new technologies and the understanding of molecular biology have created a shift in the way we understand J Bioanal Biomed the molecular basis of cell regulation and the parameters that are affected during the disease process. The advent of genomics and proteomics and automation of various technologies have created platforms that can effectively be employed to understand normal cell functions and the changes during a disease. McHugh et al., (2009); Mc Shane et al., (2009); Rajcevic et al., (2009). The sequence of the human genome and the functional proteins that are being understood as cell signal molecules have all cleared the understanding of growth and differentiation of a normal cell and also implicate several of these dynamic molecules in a disease.

\section{Molecular pathogenesis}

The complexities in biology and the molecular mechanisms of normal cell regulation is an area where scientific research always provides more information. Even though the data in this area is extremely crowded, there seems to be no stop in the unending new knowledge that is constantly appearing in cited literature. It is very well understood that a disease exerts its effect because of malfunction of these molecules and the arrest of this dysfunction could help us revert the condition and thus prevent the disease. Hasko et al., (2008); Oka et al., (2008); Shum et al., (2008).

\section{Grey areas in drug discovery research}

Several approaches based on the recent developments in different areas of modern biology have been targeted to evolve specific methods that can be used to treat diseases. With this approach in mind and the development chain as required by regulators fully understood, the development team of scientists have been working hard to crack the fundamentals of a disease and how one can stop or prevent the disease progress.

\section{Why are we behind in drug development}

Despite several advancements and huge investments, we are far behind in this pursuit. There are several reviews that highlight the difficulties one encounters in the present development cascades. The question one raises are that, from precise early discovery experiments, followed by translational studies in vari-

\footnotetext{
*Corresponding author: Balakrishnan Arun, Vice President, External Liason, Screening and Natural Products. Piramal Life Sciences Limited, 1 Nirlon Complex, Goregaon (East), Mumbai 400063,India, Tel: +91 22 30818401; Fax: +91 22 30818411; E-mail: arun.balakrishnan@piramal.com

Received November 23, 2009; Accepted December 22, 2009; Published December 22, 2009

Citation: Arun B (2009) Challenges in Drug discovery: Can We Improve Drug Development. J Bioanal Biomed 1: 050-053. doi:10.4172/1948593X.1000011

Copyright: (c) 2009 Arun B. This is an open-access article distributed under the terms of the Creative Commons Attribution License, which permits unrestricted use, distribution, and reproduction in any medium, provided the original author and source are credited.
}

ISSN:1948-593X JBABM, an open access journal 
ous animal models and then to clinical trials, there appears to be something wrong in this translation. Mager et al., (2009). All the high end predictions of the molecule based on various approaches from Chemo informatics modeling and wet lab target specific approaches like target based drug design, identifying new targets and applying new targets and identifying novel molecules from diverse sources both through the synthetic route and by scanning the biodiversity for novel molecules all appear to be failing at some level. Kochn, (2008); Rollinger et al., (2006); Rollinger et al., (2008). The drop out of molecules when moved through the development chain, despite showing very promising activities in the invitro models is high. Are these prediction models wrong or are we not able to translate these positive compounds invitro into animal models. Is there a way to increase the percentage of translation or are the animal models which we are currently employing failing at some level. These questions are difficult to answer, but an answer to such difficult questions will be important to make animal experimentation also precise and more predictive.

\section{HITS to preclinical evaluation in animal models}

This clearly points out that the various advancements in early drug discovery has increased the pipeline for early HITS and despite our strengths to improve a library of potent compounds from the biodiversity or specific synthetic chemical libraries, pipeline of new drugs is diminishing world wide.

But the question is, how can one change the current animal pharmacological parameters and models in which we are trying to extrapolate information and study different parameters that are usually studied to take decisions on whether to take a molecule forward. Just like how conventional pharmacologist question the wisdom of target based drug discovery, modeling and validation on cell lines, a scientist who understands the precision in such approaches may find it illogical when they understand on how dose for animal studies are decided and also sometimes question the validity of such models in relation to the human disease. The only answer is that there is no other rationale to examine this idea and how to take a molecule forward. Just like how biologists questioned the modern developments in molecular biology, human DNA sequencing and any precise mechanistic study during the time when these information were been published, the sceptism in these approaches were always argued upon. Many of the conventional physiologists were always opposed to such an understanding of biologists. But the new information of proteomics and genomics that evolved out of these findings has definitely contributed to the early discoveries based on many different approaches. Fabre et al., (2009); Uverdevert et al., (2009); Wentzensen et al., (2009). These approaches will probably improve our current lacunae in drug discovery.

\section{New approaches in prediction of drug efficacy in clinical trials}

My fear is that, it's time that we exploit some of the modern approaches and try to improve the development studies using better approaches in animal pharmacology, developing non invasive techniques, applying knowledge in the areas of biomarkers to hasten the understanding of the positive and negative effect of molecules in invivo pharmacology and reduce the time lines of such development. Greinert, (2009), Hasko et al., (2008); Mullar, (2009); Wentzensen et al., (2009). The lacunae is that, now we have shifted our pipeline where we have large number of potent HITS which can be developed further into a space were we still rely on primitive modes of selection criteria, animal models and approaches, where we need to apply the wisdom of modern molecular biology and pharmacogenomics information to translational studies, thus reducing the cost and also improve the bottle neck and selection criteria which will be more fool proof and robust. Fabre et al., (2009); Greinert, (2009); Uverdevert et al., (2009). I believe that the general argument that one molecule in five thousand molecules will become a drug can be improved if we develop rationale ways to defining animal experimentation, interspacing such studies with the modern concepts of molecular understanding of a disease and rationalize modalities by which we can hasten the process, such that more molecules which are defined as robust can be taken into clinics faster and with a clear understanding of the mode of action. Auffray et al., (2009); Mullar, (2009); Van et al., (2009).

Currently, 50\% lower submission of new drug applications is noted compared to a decade earlier. NCE's reaching markets annually have declined, clinical failure rates have climbed well above historic averages and mainly failures in Phase III trails have risen dramatically. What can be the reasons? Can we improve upon selection of compounds by novel technologies, which will help us to understand the negativities of a molecule in trial better before inducting it into clinical trials.

\section{High end technology platforms}

High-end platforms like microarray and real time PCR have all helped us to progressively move forward to understand the complications of control under normal situations and then compare it during a disease. These molecular studies have paved the way for us in pharmaceutical research to employ such target to effectively combat a disease. Auffray et al., (2009); Chen et al., (2009); Stimson et al., (2009); Uverdevert et al., (2009); Van et al., (2009). But despite these approaches wherein molecular mechanisms are reversed by small molecules are the major route of development of a drug, the translation of such invitro phenotypic and target based assays still lead to major failures when such active molecules are tested on animal models. Several reasons have been used to explain this defect in translation of many of the invitro positives into animal systems and the main causes are the absorption parameters or degradation of the molecule in the invivo situations. These problems are however addressed by the chemists and by developing SAR's around the new scaffold one can turn around the situation and thereby produce novel molecules that are effective in the invivo situation. However, despite the availability of effective technologies one can see a narrowing of the funnel during animal experimentation and obtaining good invivo parameters. This should be an area where one should put in new thoughts and ideas wherein we can improve the speed of assessment using such animal models. Can we rely on specific markers that can be used to address the effectiveness of the molecule invivo.

The other major lacunae both in terms of time and money are the studies in humans. The translation from animal models 


\section{Journal of Bioanalysis \& Biomedicine - Open Access JBABM/Vol.1 Issue 1}

to human trials is also a major problem, because in most cases what one sees in animals need not be the case in the humans and despite all the effective controls we take to design an animal studies we will end up in toxicity during long term studies. Auffray et al., (2009); McHugh et al., (2009); McShane et al., (2009); Rajcevic et al., (2009); Van et al., (2009).

\section{Prediction of behaviour of molecules in clinic: biomarkers}

Can we predict on how the molecule will respond in human trials using the modern technologies available. This will help us to cut short clinical trials in terms of years and in terms of cost. Auffray et al., (2009); Chen et al., (2009); Greinert, (2009); Stimson et al., (2009), Van et al., (2009); Wentzensen et al., (2009).

Predicting human clinical efficacy is a complex challenge and can be addressed if the mechanism of action of the drug and the target can be validated. The novel approaches available today can be exploited to study the compound action. Between 1991 to 2001, the failure in drug discovery has been attributed to pharmacokinetics reasons, absorption, and destruction of tissue, localization, duration of action and excretion to toxicology and clinical safety, even target-based discovery approaches does not seem to have eased the solution. Thus, pharmaceutical industry faces unprecedented challenges, as nated during this period. Hence, we believe there is a growing need to modernize drug development process and incorporate advance in science and technology into a new development model.

\section{Pharmacogenomics in clinical design}

Although a great deal of information can be obtained from invitro phenotypic and target based assays on the possible mechanism of action of a small molecule. It is still difficult to predict whether these molecules, which are so effective invitro, can really pass through several of the preclinical studies. Fabre et al., (2009); Rollinger et al., (2008); Taketo et al., (2009). Is there a way to improve the prediction and improve the effectiveness of animal studies. Pharmacological studies surely do give us immense confidence and measures that enable us to translate the effects from animal models to Humans. Abreu et al., (2007); Hegen et al., (2007); Shum et al., (2008); Uverdevert et al., (2009). This could be an area where technology, information on molecular biology and clinical pharmacology can all work together to evolve better prediction models which will then be useful to improve the information on the action of such molecules in a dynamic situation where several of the pharmacological parameters will assess the potential of the molecule to move forward in the development chain.

In order to effectively improve the success of molecules in trials, predicting human clinical efficacy is a complex challenge. Utlising the molecular concepts of understanding disease, we must address to identify truly therapeutic targets, prioritize those targets and set scientific foundation for future decisions including trial design. Targets with high probability of clinical efficacy would progress in the pipeline. Extrapolation of data from an isolated biological response of a gene or a molecule level to a system side effects of response will help us problems. The current reasons of drug failures are mainly due number of new molecule entities approved by FDA has stag-

in prediction of clinical efficacy of a compound and also predict the side effects. Methods to improve prediction of clinical efficacy is an application that needs to be addressed, only then the applications of smart technologies in early phase of drug discovery can be translated smoothly into the clinics.

\section{Acknowledgements}

My sincere thanks to Ms.Sheila Vaz for her typographical and editorial assistance of this document. The author also acknowledges the valuable support of Dr Somesh Sharma, Managing Director, Piramal Life Sciences Limited.

\section{References}

1. Abreu MT, Sparrow MP (2007) The role of translation and research in inflammatory bowel disease. Rev Gastroenteral Mex 72: 146-53. » CrossRef » PubMed » Google Scholar

2. Auffray C, Chan Z, Hood L (2009) Systems Medicine: the future of medical genomic and healthcare. Genome Med 20: 1-2. »CrossRef » PubMed » Google Scholar

3. Bryan NS, Bian K, Murad (2009) Discovery of the nitric oxide signaling pathway and targets for drug development. Front Biosci 14: 1-18. » CrossRef »PubMed » Google Scholar

4. Chen JN, Ni RZ, Xiao HB, GuoJG, Zhar JW (2009) Comparative proteomic analysis of differentially expressed proteins in human pancreatic tissue. Hepatobiliary Pancreat Dis Int 2: 193-280. »CrossRef » PubMed » Google Scholar

5. Fabre N, Anglade I, Vericat JA (2009) Application of toxic genomic tools in the drug research and development process. Toxicol Lett 186: 13-17. »CrossRef » PubMed » Google Scholar

6. Gonzalez-Sanchez JL, Serram-Rios M (2007) Molecular basic of insulin action. Drug New Perspect 20: 527-31. »CrossRef » PubMed » Google Scholar

7. Greinert R (2009) Skin Cancer: new markers for better prevention. Pathobiology 71: 64-81. »CrossRef » PubMed » Google Scholar

8. Hegen M, Keith JC Jr, Collins M, Nickerson-Nulter CL (2007) Utility of animal models for identification of potential therapeutics for rheumatoid arthritis. Ann Rheum Dis 67: 1505-15. »CrossRef » PubMed » Google Scholar

9. Hart WN, Hambley TW (2009) Targeted cancer therapeutics. Cancer Res 69: 1263-7. »CrossRef » PubMed » Google Scholar

10. Hasko G, Linden J, Cronstein B, Pacher P (2008) Adenosine receptors: therapeutic aspects for inflammatory and immune diseases. Nat Rev Drug Discovery 9: 759-70. » CrossRef » PubMed » Google Scholar

11. Kochn FE (2008) High impact technologies for natural products screening. Prog Drug Res 65: 175, 177-210. » CrossRef » PubMed » Google Scholar

12. Matta A, Ralhan R (2009) Overview of current and future biologically based targeted therapies in head and neck squamous cell carcinoma. Head and Neck Oncol 2: 1-6. »CrossRef » PubMed » Google Scholar

13. Mager DE, WOO S, Jusko WJ (2009) Scaling pharamacodynamics from invitro and preclinical animal studies to humans. Drug Metab Pharmacokinet 24: 16-24. » CrossRef » PubMed » Google Scholar

14. McGeer EG, McGeer PL (2007) The role of anti-inflammatory agents in Parkinsons disease. CNS Drugs 21: 789-97. »CrossRef » PubMed » Google Scholar

15. Mullar BA (2009) Imatinib and its successors-how modern chemistry has changed drug development. Current Pharma Des 15: 120-33. "CrossRef » PubMed » Google Scholar

16. McHugh SM, O’Donnell J, Gillen P (2009) Genomic and Oncoproteomic advances in detection and treatment of colorectal cancer. World J Surg Oncol 1: 36. » CrossRef » PubMed » Google Scholar

17. McShane LM, Humberger S, Adjee AA (2009) Effective incorporation of biomarker into phase II trials. 15: 1898-905. »CrossRef » PubMed » Google Scholar

J Bioanal Biomed
Volume 1(1) : 050-053 (2009) - 052 
Citation: Arun B (2009) Challenges in Drug discovery: Can We Improve Drug Development. J Bioanal Biomed 1: 050-053. doi:10.4172/ 1948-593X.1000011

18. Oka M, Fagan KA, Jones PL, Mc Murtrgie (2008) Therapeutic potential of RhoA/Rho Rinase inhibitors in pulmonary hypertension. Br J Pharmacol 155: 444-54. » CrossRef » PubMed » Google Scholar

19. Rajcevic U, Niclou SP, Jinenez CR (2009) Proteomics strategies for target identifications and biomarker discovery in cancer. Front Biosci 14: 3292-303. »CrossRef » PubMed » Google Scholar

20. Rollinger JM, Langer T, Stuppner H (2006) Strategies for efficient lead structure discovery from natural products. Cur Med Chem 13: 1491-507. »CrossRef » PubMed » Google Scholar

21. Rollinger JM, Langer S (2008) Virtual screening for the discovery of bioactive natural products. Prog Drug Res 65: 211, 213-49. » CrossRef » PubMed » Google Scholar

22. Stimson L, LaThangue NB (2009) Biomarkers for predictions clinical response to HDAC inhibitors. Cancer Lett. »CrossRef » PubMed » Google Scholar
23. Shum BO, Rolph MS, Sewell WA (2008) Mechanisms in allergic airway inflammations - lessons from studies in the mouse. Expert Rev Mol Med 27: 10-15. » CrossRef » PubMed » Google Scholar

24. Taketo MM, Edelman W (2009) Mouse models of colon cancer. Gastroenterology 36: 780-98. »CrossRef » PubMed » Google Scholar

25. Uverdevert JB, Theodorescu D, Lee JK (2009) Utilizing the molecular gateway: the path to personalized cancer management. Clin Chem 55: 684-97. »CrossRef » PubMed » Google Scholar

26. Van QW, Veenstra TD (2009) How close is the bench to the bedside? Metabolic profiling in cancer research. Genome Med 1: 5. »CrossRef » PubMed » Google Scholar

27. Wentzensen N, Klug SJ (2009) Cervical cancer control in the era of HPV vaccination and novel biomarkers. Pathobiology 76: 82-9. »CrossRef » PubMed » Google Scholar 